\title{
Обґрунтування концептуальних підходів щодо отримання енергії без витрати енергоносіїв
}

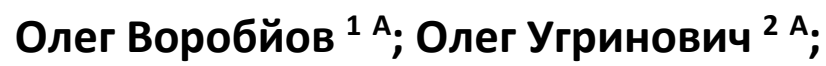 \\ Микола Клонцак ${ }^{3}$; ; Сергій Кондратюк 4 А \\ А Національний університет оборони України імені Івана Черняховського, пр-кт Повітрофлотський 28, м. Київ, 03049, Україна
}

Received: January 25, 2020 | Revised: February 20, 2021 | Accepted: February 28, 2021

DOI: $10.33445 /$ sds.2021.11.1.8

\begin{abstract}
Анотація
Стаття присвячена вирішенню проблем забезпечення енергією промислових галузей i об'єктів, транспортних засобів, особистих потреб людини та взагалі енергетичної безпеки майбутніх поколінь людства.

Проведений аналіз наукових робіт в цій галузі і визначено, що ставка робиться на видобуток та використання альтернативних видів енергії, що не змозі забезпечити все збільшуючи потреби людства.

Пропонуються концептуальні підходи щодо отримання енергії на основі наукової гіпотези отримання енергії без витрати енергоносіїв. В цьому випадку, традиційні теплова, електрична, гравітаційна, світлова, звукова, вітрова, гідравлічна, біологічна і інші види енергії $\epsilon$ лише способами передачі, транспортування енергії, а не самою енергією. Енергія характеризується величинами коливальних параметрів хвиль випромінювання і займаним простором з певною щільністю енергії.

На основі цих підходів відбувається активація палива, його енергезація, тобто підвищення енергетичної ефективності теплом відпрацьованих газів. Залежно від видів палив i пристроїв, де вони використовуються, при одному і тому ж кінцевому результаті витрата енергоносіїв, можливо, зменшена на 10-80 \%. При цьому забезпечується повне згорання кожного окремого компоненту палива. Одночасно вирішуються не тільки енергетичні завдання, але і вельми складні екологічні проблеми.

В подальшому пропонується обґрунтувати вимоги до приладів перетворення видів енергії для цих перспективних двигунів.
\end{abstract}

Ключові слова: енергія, випромінювання, хвиля, енергоносії, синтез, резонанс.

\section{Постановка проблеми}

В останні роки, у зв'язку з загрозою повного вичерпання запасів природних вуглеводнів, дуже гостро стоїть проблема перспективного енергетичного забезпечення промислових галузей і об'єктів, транспортних засобів, особистих потреб людини та взагалі енергетичної безпеки майбутніх поколінь людства.

\section{Аналіз останніх досліджень та публікацій}

Для вирішення цієї проблеми в роботах [1-5] пропонуються використання альтернативних видів енергії таких, як сонячна, вітрова, світлова, ядерна, гравітаційна, електромагнітна, внутрішня енергії, енергія мас води світового океану та інші види енергетичних взаємодій. На використанні цих видів енергії побудовані

\footnotetext{
${ }^{1}$ Corresponding author: д.т.н., професор, професор кафедри тилового забезпечення інституту, e-mail: oleg33377@ukr.net

2 к.в.н., доцент, професор кафедри тилового забезпечення, e-mail: olegenya999@gmail.com

${ }^{3}$ к.в.н., професор кафедри військової підготовки, e-mail: 0678660359@ukr.net

${ }^{4}$ старший викладач кафедри тилового забезпечення, e-mail: prodpivnich@ukr.net
} 
відповідні джерела та споживачі цих видів енергії. Однак, це далеко не задовольнило все збільшуючи потреби людства в виробітку і постачанні енергії та не зважаючи на досить великі успіхи в будівництві різних типів машин і двигунів на альтернативних видах пального, не склалося гарантованих передумов для відказу від традиційних видів енергоресурсів, а навпаки через сукупність відповідних причин проявляється тенденція до збільшення їх добичі і відповідно збільшення залежності від них.

\section{Постановка завдання}

Метою статті $\boldsymbol{\epsilon}$ обґрунтування концептуальних підходів щодо отримання енергії на основі наукової гіпотези отримання енергії без витрати енергоносіїв і визначити умови за яких можливо забезпечити цей процес.

\section{Виклад основного матеріалу}

Згідно теорії американського вченого Джорджа Гамова [6] передуючий Всесвітом величезна вогненна куля до великого вибуху складалася в основному з неймовірно великої щільності випромінювань і, в незначній частині, з ще більшою щільністю концентрацій все тих же випромінювань з сумарною енергією елементарних частинок кожна.

Таким чином, первинною (первісною) субстанцією, суттю всього єства $€$ випромінювання. Супю випромінювання $\epsilon$ коливальні зміни енергії від одного якогонебудь крайнього стану до іншого, тобто від min до max або від max до $\min$ і так постійно. Причому, переходи випромінювання з одного якого-небудь крайнього енергетичного стану в інший крайній енергетичний стан проходять миттєво, без витрат часу. Кожне випромінювання характеризується величинами властивих йому коливальних (енергетичних) параметрів. Це може бути чинником, що визначає кількість енергоінформаційних випромінювання, і, таким чином це $\epsilon$ посередником взаємодій випромінювання, що несуть енергію, і складових спектру випромінювання навколишнього середовища. Енергоінформаційні випромінювання як генеруються, так поглинаються відповідним випромінюванням, тобто постійно трансформуються [7].

Кожна хвиля випромінювання $\epsilon$ носієм (транспортом) енергії. 3 підвищенням частоти і амплітуди коливань в результаті інтерференційних і (або) резонансних взаємодій енергії хвиль випромінювання енергоінформація про ці випромінювання зростатиме, що є цілком природним.

у тривимірному просторі хвилі випромінювання розповсюджуються на всі боки, тобто заповнюють об'єм простору відносно початку (точки відліку) випромінювання. Енергетично кожна хвиля випромінювання проявляє себе в навколишньому просторі амплітудою, тобто їі величиною, а точніше чисельним її значенням. Отже, енергія одного випромінювання в просторі буде кубом амплітуди. Аналогічно, об'єм простору, заповненого енергією однієї хвилі випромінювання, символічно можна позначити як куб довжини хвилі. Відношення кількості енергії, випромінювання, що полягає в одній хвилі, в просторі до об'єму, займаного енергією цієї хвилі, характеризуватиме щільність енергії випромінювання в об'ємі простору, займаного однією хвилею випромінювання.

В цьому випадку, хвилю випромінювання складно представити синусоїдою (косинусоїдою) 3 ії плавними змінами величин і напрямів коливальних параметрів, що містять і розкривають суть самого випромінювання. Хвиля випромінювання це зміни енергетичного стану випромінювання, перехід енергії випромінювання 3 одного в інше крайні стани, тобто від $\min$ до max i (або) навпаки. Причому зміни ці відбуваються в результаті миттєвих переходів від $\min$ до $\max$ і (або) навпаки, без витрат часу [8].

Якщо який-небудь енергетичний стан ( $\mathrm{min}$ або $\max$ ), хвилі випромінювання представити кубиком одного якого-небудь кольору, а 
інший енергетичний стан (min і $\max )$ хвилі випромінювання представити кубиком такого ж розміру, але якого-небудь іншого кольору, то сумістивши площини цих двох різноколірних кубиків, ми отримаємо модель енергетичних станів хвилі випромінювання в одному якому-небудь напрямі горизонтальному або вертикальному.

Для уявлення, таким чином, моделі енергії хвилі випромінювання, що розповсюджується в тривимірному просторі, необхідно по 4 кубики різного кольору, тобто всього 8 кубиків. В цьому випадку, довжина ребра одного кубика представлятиме величину амплітуди, а двох перпендикулярних до нього ребр - довжину хвилі.

Робимо висновок, що кількість перебувань хвилі, тобто енергії в тому або іншому $\min$ або max стані в одиницю часу $\epsilon$ частотою коливань (змін) енергетичних станів (хвиль) випромінювання.

Співпадаючі по величинах коливальних параметрів (когерентні) хвилі випромінювання, які взаємодіють між собою на принципі суперпозиції, інтерференційно складаються і утворюють, таким чином, концентратори енергій випромінювання. Такими найбільш енергетично стійкими енергоутвореннями можуть бути елементарні частинки і утворення з них [8].

Залежно від кількості і величини коливальних параметрів хвиль випромінювання елементарні частинки, що складаються 3 них, можуть бути різними за своїми енергетичними значеннями. Однакові і різні елементарні частинки можуть утворювати в різних поєднаннях крупніші енергетичні з'єднання, аж до частинок ядра атомів хімічних елементів речовин. Електрони в цьому випадку, очевидно, характеризуватимуться не негативним електричним зарядом, а кількістю вмісту в них енергії, але не із співпадаючими значеннями певних величин абсолютно різних коливальних параметрів електронів. Концентратори енергії хвиль випромінювання завжди мають свої власні величини коливальних параметрів, абсолютно не співпадаючих 3 аналогічними величинами хвиль випромінювання, що їх створюють. Причому, здійснено очевидно, що виходячи з логічних міркувань, із збільшенням енергії новоутворених енергоконцентраторів частота їх власних коливань зменшуватиметься, а амплітуда і довжина хвилі збільшуватимуться. Звідси витікає практичне визначення енергостану концентраторів енергії по величинах коливальних параметрів хвиль випромінювання, що змінюються, тобто по лінійних розмірах амплітуди, довжини хвилі і по частоті власних коливань концентраторів випромінювання.

Особливою характеристикою енергії випромінювання може бути її щільність в одиниці об'єму. І це $\epsilon$, мабуть, величиною головною в цьому випадку для енергетичної характеристики якого б то не було фізичного об'єкту.

В цьому випадку, традиційні теплова, електрична, гравітаційна, світлова, звукова, вітрова, гідравлічна, біологічна і інші види енергії $\epsilon$ лише способами передачі, транспортування енергії, а не самою енергією. Енергія характеризується величинами коливальних параметрів хвиль випромінювання i займаним простором 3 певною щільністю енергії.

Вплив кількості енергії, що міститься в одиниці об'єму енергоносіїв, у тому числі і традиційних, можна привести на простих прикладах. Відношення бажаного результату до дії, направленої на отримання цього результату визначається часом, тобто, чим ефективніше дія, тим менше часу необхідно для отримання заданого результату і навпаки. Якщо дія прагне до $\mathrm{min}$, час спрямовується до нескінченності. Так, якщо паливо в сучасних теплових двигунах направити зустрічним потоком до руху відпрацьованих газів, аж до камери згорання, без дії окислювача, відбувається нагрів палива до розриву енергетичних зв' язків його компонентів.

Таким чином, відбувається активація палива, його енергезація, тобто підвищення енергетичної ефективності теплом відпрацьованих газів. Залежно від видів палив і пристроїв, де вони використовуються, при одному і тому ж кінцевому результаті витрата енергоносіїв, можливо, зменшена на $10-80 \%$. 
При цьому забезпечується повне згорання кожного окремого компоненту палива. Одночасно вирішуються не тільки енергетичні завдання, але і вельми складні екологічні проблеми.

Максимальна температура згорання, наприклад метану, у відкритій атмосфері досягає небагато чим більш $1500^{\circ} \mathrm{C}$, та і то не у всьому полум'ї, а тільки в незначному його об'ємі. Хоча метан, як відомо [8], за певних умов, може згорати і давати температуру до $150000^{\circ} \mathrm{C}$.

Попереднє, послідовне нагрівання вуглеводневого палива постійним збільшенням приросту температури в часі до максимально можливої температури в зоні горіння з подальшим спалюванням, підвищує температуру його горіння приблизно на температуру нагріву. Аналогічні температурні зміни відбуваються на наступному витку, але вже на значно вищому температурному ступені 3 одночасним підвищенням температури палива i його горіння. Це ефект теплового резонансу енергії.

Першим обмеженням в цьому випадку $\epsilon$ невідповідні вимоги по термостійкості, жароміцності конструкційних матеріалів. I проте, попередні розрахунки показують, що тепловий двигун (сучасний має ККД 0,2-0,3), що працює на цьому принципі, може розвивати потужність 100 к.с. на 1 кг маси двигуна із значним (у декілька разів) зменшенням питомої витрати палива на одиницю потужності і ККД не нижче 0,9.

Отже, величини (числові значення) коливальних параметрів визначають по енергії (енергетичному стану) кожної хвилі випромінювання, оскільки коливання за своєю сутю $\epsilon$ постійною зміною величин коливальних параметрів в часі. У крайніх точках ці зміни мають одне з двох значень - min або max. Енергія хвилі випромінювання в таких випадках завжди знаходиться в одному зі своїх енергетичних станів - $\min$ або max. Причому, діапазон величин коливальних параметрів, що визначає крайні енергетичні стани випромінювання в просторі Всесвіту, не може мати яких-небудь обмежень. Зміни цих величин походять від нескінченно великих значень до нескінченно малим і (або) навпаки. Час перебування в цих станах рівне для обох крайніх станів - min або max. А самі стани дискретні. Кількість тривалості перебувань випромінювання в тому або іншому крайньому енергетичному стані в одиницю часу $є$ частотою змін енергетичних станів випромінювання. Амплітуда, як параметр коливальних змін, у такому разі $€$ визначником енергетичного стану випромінювання, тобто по величині амплітуди можна судити про кількість енергії в крайніх енергетичних станах випромінювання. Звідси витікає, що енергія - це зміна величин коливальних параметрів станів (хвиль) випромінювання. А тепло, звук, електрика, різного походження поля, механічна сила i інерція, гравітаційні і хімічні взаємодії, каталіз, фармацевтичні і гуморальні (ферменти, гормони, імуноглобулін і інші) дії в біофізичних об'єктах фауни, принципи роботи К-, Na-, Caвих насосів в живих клітинах і тому подібне все це способи передачі енергії за допомогою випромінювання [8].

Коливання взагалі, а гармонійні зокрема, у тому числі і випромінювання, володіють унікальною властивістю резонувати [8]. Це стан випромінювання, коли відбувається різка активація їх взаємодій. Практично вибухом відроджується (синтезується) енергія резонансних коливань хвиль випромінювання.

Керованість резонансом у такому разі дозволяє управляти синтезом енергії резонансних випромінювання. Причому, енергія резонансних коливань в принципі, а випромінювання в цьому випадку не $\epsilon$ виключенням, на багато порядків, і навіть на десятки порядків, перевершує енергію збудження резонансних коливань.

\section{Висновки}

В результаті відкриваються по суті необмежені можливості виробництва енергії без витрати енергоносіїв, як це має місце в тій, що оточує нас реальній Природі. Наприклад, починаючи з "Великого вибуху", відроджена $з$ випромінювання, такий, що постійно 
розширюється в просторі і вельми стійко існує в часі Всесвіт.

Враховуючи миттєвість змін енергетичних станів випромінювання, де, як і на субмикрорівні енергетичних взаємодій елементарних частинок закони збереження не діють то реальне виробництво енергії резонансних випромінювання, у такому разі, $\epsilon$ практично безкоштовним, за винятком разових витрат на придбання безсервісних пристроїв автономного і індивідуального призначення та виконання і без обмежень у витраті енергії споживачами.

Таким чином в статті запропоновані концептуальні підходи щодо отримання енергії на основі наукової гіпотези отримання енергії без витрати енергоносіїв і визначені умови за яких можливо забезпечити цей процес.

В подальшому пропонується обґрунтувати вимоги до приладів перетворення видів енергії для цих перспективних двигунів.

\title{
Список використаних джерел
}

1. Германович В. Альтернативные источники энергии и энергосбережение. Практические конструкции по использованию энергии ветра, солнца, воды, земли, биомассы. Москва, 2014. С. 320.

2. Сибикин Ю. Д. Нетрадиционные и возобновляемые источники энергии. Москва, 2012. С. 240.

3. Володин В. Энергия, век двадцать первый. Москва, 1998. С. 248.

4. Уделл Свен. Солнечная энергия и другие альтернативные источники энергии. Москва, 2000. С. 88.
5. Арустамов Э. А. Экологические основы природопользования. Москва, 2002. С. 187.

6. Gamow G. Thirty Years that Shook Physics. Doubledcy, 1966. Р. 233.

7. Кравец И. А. Сатумная энергия - это энергия из энергии. Киев, 2002. С. 39-51.

8. Кравец И. А. Управляемый синтез энергии. Харьков, 2001. С. 298

9. Tvanov V. Elektrodymamics and UHF devices: Lecture synopsis. Kyiv, 2002. P. 128.

\section{Обоснование концептуальных подходов к получению энергии без расхода энергоносителей}

\author{
Олег Воробьёв 1 А; Олег Угринович 2 А; \\ Николай Клонцак ${ }^{3}$; ; Сергей Кондратюк 4 A \\ ${ }^{1}$ Corresponding author: д.т.н., профессор, профессор кафедры тылового обеспечения, e-mail: oleg33377@ukr.net \\ 2 к.в.н., доцент, профессор кафедры тылового обеспечения, e-mail: olegenya999@gmail.com \\ ${ }^{3}$ к.в.н., профессор кафедры военной подготовки, e-mail: 0678660359@ukr.net \\ ${ }^{4}$ старший преподаватель кафедры тылового обеспечения, e-mail: prodpivnich@ukr.net
}

А Национальный университет обороны Украины имени Ивана Черняховского, пр-кт Воздухофлотский, 28, г. Киев, 03049, Украина

\begin{abstract}
Аннотация
Статья посвящена решению проблем обеспечения энергией промышленных отраслей и объектов, транспортных средств, личных потребностей человека и вообще энергетической безопасности будущих поколений человечества.

Проведен анализ научных работ в этой области и определено, что ставка делается на добычу и использование альтернативных видов энергии, что не в состоянии обеспечить все увеличивающие потребности человечества.

Предлагаются концептуальные подходы по получению энергии на основе научной гипотезы получения энергии без затраты энергоносителей. В этом случае, традиционные тепловая, электрическая, гравитационная, световая, звуковая, ветровая, гидравлическая, биологическая и другие виды энергии является лишь способами передачи, транспортировки энергии, а не самой энергией. Энергия характеризуется величинами
\end{abstract}


колебательных параметров волн излучений и занимаемым пространством с определенной плотностью энергии.

На основе этих подходов происходит активация топлива, его енергезация, то есть повышение энергетической эффективности теплом отработанных газов. В зависимости от видов топлив и устройств, где они используются, при одном и том же конечном итоге расход энергоносителей, возможно уменьшить на 10-80\%. При этом обеспечивается полное сгорание каждого отдельного компонента топлива. Одновременно решаются не только энергетические задачи, но и весьма сложные экологические проблемы.

В дальнейшем предлагается обосновать требования к приборам преобразования видов энергии для этих перспективных двигателей.

Ключевые слова: энергия, излучение, волна, энергоносители, синтез, резонанс.

\title{
Justification of conceptual approaches to producing energy without energy carrier consumption
}

\author{
Oleh Vorobiov ${ }^{1}$ A; Oleh Uhrynovych ${ }^{2}$ A; \\ Mykola Klontsak ${ }^{3}$; ; Serhii Kondratiuk ${ }^{4 \text { A }}$ \\ ${ }^{1}$ Corresponding author: Doctor of Technical Sciences, Professor, Professor of Department of Logistics, e-mail: oleg33377@ukr.net \\ ${ }^{2}$ Candidate of Military Sciences, Associate Professor, Professor of Department of Logistics, e-mail: olegenya999@gmail.com \\ ${ }^{3}$ Candidate of Military Sciences, Professor of military Department, e-mail: 0678660359@ukr.net \\ ${ }^{4}$ Senior lecturer of the Department of Logistics, e-mail: prodpivnich@ukr.net \\ A National Defence University of Ukraine named after Ivan Cherniachovskyi, 28, Povitroflotsky, ave, Kyiv, 03049, Ukraine
}

\begin{abstract}
The article is devoted to solving the problems of providing energy to industrial sectors and objects, vehicles, personal needs of a person and, in general, energy security of future generations of mankind.

An analysis of scientific works in this area is carried out and it is determined that the stake is placed on the extraction and use of alternative types of energy, which is not able to meet the ever-increasing needs of mankind.

Conceptual approaches to energy production are proposed based on the scientific hypothesis of energy production without the consumption of energy carriers. In this case, traditional thermal, electrical, gravitational, light, sound, wind, hydraulic, biological and other types of energy are only ways of transferring, transporting energy, and not energy itself. Energy is characterized by the values of the vibrational parameters of the radiation waves and the occupied space with a certain energy density.

On the basis of these approaches, the fuel is activated, it is energized, that is, the energy efficiency is increased by the heat of the exhaust gases. Depending on the types of fuels and devices where they are used, with the same final result, the consumption of energy carriers can be reduced by $10-80 \%$. This ensures complete combustion of each individual fuel component. At the same time, not only energy problems are being solved, but also very complex environmental problems.

In the future, it is proposed to substantiate the requirements for devices for converting energy types for these promising engines.
\end{abstract}

Keywords: energy, radiation, wave, energy carriers, synthesis, resonance.

\section{References}

1. Germanovich V. Alternative energy sources and energy saving. Practical designs for the use of wind, sun, water, earth, biomass energy. Moscow, 2014. P. 320.
2. Sibikin Yu. D. Non-raditional and renewable energy sources. Moscow, 2012. P. 240.

3. Volodin V. Energy, twenty first century. Moscow, 1998. P. 248. 
4. Udell Sven. Solar energy and other alternative energy sources. Moscow, 2000. P. 88.

5. Arustamov E. A. Ecological foundations of nature management. Moscow, 2002. P. 187.

6. Gamow G. Thirty Years that Shook Physics. Doubledcy, 1966. P. 233.
7. Kravets I. A. Satumic energy is energy from energy. Kiev, 2002. P. $39-51$.

8. Kravets I. A. Controlled energy synthesis. Kharkov, 2001. P. 298.

9. Tvanov V. Elektrodymamics and UHF devices: Lecture synopsis. Kyiv, 2002. P. 128. 